\title{
Synthesis and Characterization of Silicate Gel by using Sol-gel Process: Experiments and DFT calculations
}

\author{
Anas Driouich, Safae El Alami El Hassani, Fatimazahra Chajri, Ouafae Britel, Khalid Digua and \\ Hassan Chaair *
}

Laboratory of Process Engineering and Environnement, Faculty of Sciences and Technology, University Hassan II, Mohammedia, Morocco

\begin{abstract}
The synthesis of geopolymers requires the formation of an irreversible gel. This gel is produced by the sol-gel process using sodium silicate and hydrochloric acid reagents. On the one hand, the experimental study of the gelling reaction shows that for concentrations of hydrochloric acid varying between $0.5-2.0 \mathrm{~mol} / \mathrm{L}$ and concentration of sodium silicate varying between 1.0-6.0 mol/L, three reaction products are obtained. The first product is a clear solution, the second product is a reversible gel, and the last product is an irreversible gel. The products obtained are characterized by SEM, X-Ray Diffraction, FTIR spectroscopy and EDS Spectroscopy techniques. The microstructural analyzes of the two gels revealed that these obtained solids are almost similar whereas the structural and elementary analyzes show that the silica content in the irreversible gel is higher than the silica content in the reversible gel. On the other hand, the theoretical study of the reactivity of gelling, defined via the conceptual density functional theory (CDFT) combined with functional B3LYP function with a 6-31G base (d). They are allowed us to define the global and local reactivity indexes of two reagents, sodium silicate and hydrochloric acid.
\end{abstract}

Keywords: Geopolymers; Sol-gel; irreversible gel; FTIR; X-Ray Diffraction; CDFT.

\section{Introduction}

Binders have been described as being an essential part, promoting agglomeration, following a binding force in the final product. A binder can be in various forms, in particular, liquid or solid forming a matrix or a bridge ${ }^{1}$. The most used binder is cement. It is a mineral powder that behaves like a hydraulic binder and can thus harden by a chemical reaction in contact with water ${ }^{1}$.

In recent years, a new technology of mineral binders attracted great interest among researchers, especially geopolymers ${ }^{2,3}$. The consolidation of these materials is governed by a reaction between aluminosilicate powders such as fly ash, volcanic slag, kaolin and calcined kaolin (metakaolin) at a temperature above $750^{\circ} \mathrm{C}$, and a concentrated alkaline solution ${ }^{4}$. The consolidation of geopolymer materials requires the formation of a silicate gel (irreversible) which nature provides a material that serves either as an alternative cement to Portland cement or as an ecological concrete. The synthesis of silicate gel is based on the use of sodium silicates, considered one of the oldest classes of chemical products. They are now used as raw materials for the production of silica precipitates or zeolites and inorganic binders. They are also

*Corresponding author: Hassan Chaair

Email address: hass.chaair@gmail.com

DOI: http://dx.doi.org/10.13171/mjc9602001011134hc employed as binders for the development of geopolymers ${ }^{5,6}$.

Sodium silicate binders are very active, applied for agglomeration processes that combine or consolidate fine or small particles into larger units ${ }^{7,8}$. These alkali silicate solutions are also used to form silica gels under an acidic or weakly basic medium in the diluted system ${ }^{9,10}$ Studies based on the formation of gel in a strongly basic medium $(\mathrm{pH}=10)$ by acidification of a concentrated sodium silicate lead to the production of different types of gels by gradually decreasing the $\mathrm{pH}$ remaining in basic medium ${ }^{11,12}$.

Scholars have already carried out studies on reactive solutions of alkali silicate, characterized by a $\mathrm{SiO}_{2} / \mathrm{Na}_{2} \mathrm{O}$ ratio of (3.3-3.4) ${ }^{13}$. These studies have shown that these solutions are structural complexes with two relative fractions: the first fraction has a low molecular weight, while the second is dominated by a large number of silica clusters ${ }^{14,15}$.

Combined analyzes of ${ }^{29} \mathrm{Si}$ NMR, SAXS and ICPAES experiments on sodium silicate have shown that the observed high solubility of the siliceous species, resulting from acidification by an acidic solution results from the formation of a neutral complex $\mathrm{Si}_{7} \mathrm{O}_{18} \mathrm{H}_{4} \mathrm{Na}_{4}$ for a concentration of $\mathrm{Si}>4 \mathrm{~mol} / \mathrm{L}^{6,7}$. 
Other studies have shown that the entities detected by SAXS are second time large in most of the solutions prepared as in the concentrated solution. This is explained by the appearance of a polycondensation reaction between a limited number ${ }^{8}$.

The synthesis of alkaline silicate gels is obtained by the use of the sol-gel process ${ }^{16}$. The advantage of this technology is that it offers materials of high homogeneity and purity at lower temperatures than conventional methods. The principle of sol-gel is based on the use of solutions containing reactive precursors, such as alkoxides or metal salts ${ }^{4}$. The synthesis process breaks down into two main stages, namely hydrolysis (action of water) and condensation (formation of a covalent network) ${ }^{17}$.

The purpose of this work is to study the products obtained by attacking sodium silicate solutions at different concentrations with dilute solutions of hydrochloric acid ${ }^{18}$. Different experimental techniques have been used for the characterization of the samples: structural analyzes by Attenuated Total Reflectance-Fourier Transform Infra-Red spectroscopy (ATR-FTIR) and X-ray diffraction (XRD), as well as microstructural analyzes by Scanning Electron Microscope (SEM) and chemical analysis with Energy Dispersive Spectroscopy EDS.

A theoretical investigation of reactivity is also discussed in this work by using theoretical reactivity indices based on the conceptual density functional theory (CDFT) 19,20 with the correlation-exchange functional (B3LYP) ${ }^{21}$ on the basis 6- 31G (d) level set ${ }^{22}$ in the presence of the water solvent.

\section{Experimental and theoretical methods}

\subsection{Experimental section \\ 2.1.1. The initial solutions}

The sodium silicate (aqueous product) solution used is a commercial product of Scharlau Chemie S.A had the following characteristics $\left(\mathrm{Na}_{2} \mathrm{SiO}_{3}, \mathrm{Na} 37.67 \%\right.$, O $39.32 \%$, Si 23.01\%). The physicochemical characteristics of the solution are: relative density = $1.33, \mathrm{pH}=11.56,[\mathrm{Si}]=7.01 \mathrm{~mol} / 1$ and $\mathrm{Si} / \mathrm{Na}=1.71$.

Dilute solutions of hydrochloric acid have been used to modify [Si]. These solutions were prepared from a commercial solution containing $37 \%$ by weight of $\mathrm{HCl}$ (Sigma-Aldrich) by adding distilled water.

\subsubsection{Experimental protocol}

The mixtures studied were obtained by progressive addition of an $\mathrm{HCl}$ solution with concentration varying from $(0.5-2.0 \mathrm{~mol} / \mathrm{L})$, in the sodium silicate solution prepared with magnetic stirring at room temperature (Figure 1). Commercial solutions were first diluted with distilled water before acidification. The solutions obtained had a silicon concentration ranging from (1.0-6.0 mol/L). The homogeneous solutions obtained (mixtures) are then transferred to plastic containers for aging at room temperature. The $\mathrm{pH}$ value was measured all along the process using a PHM240 METER LAB pH meter (radiometer).

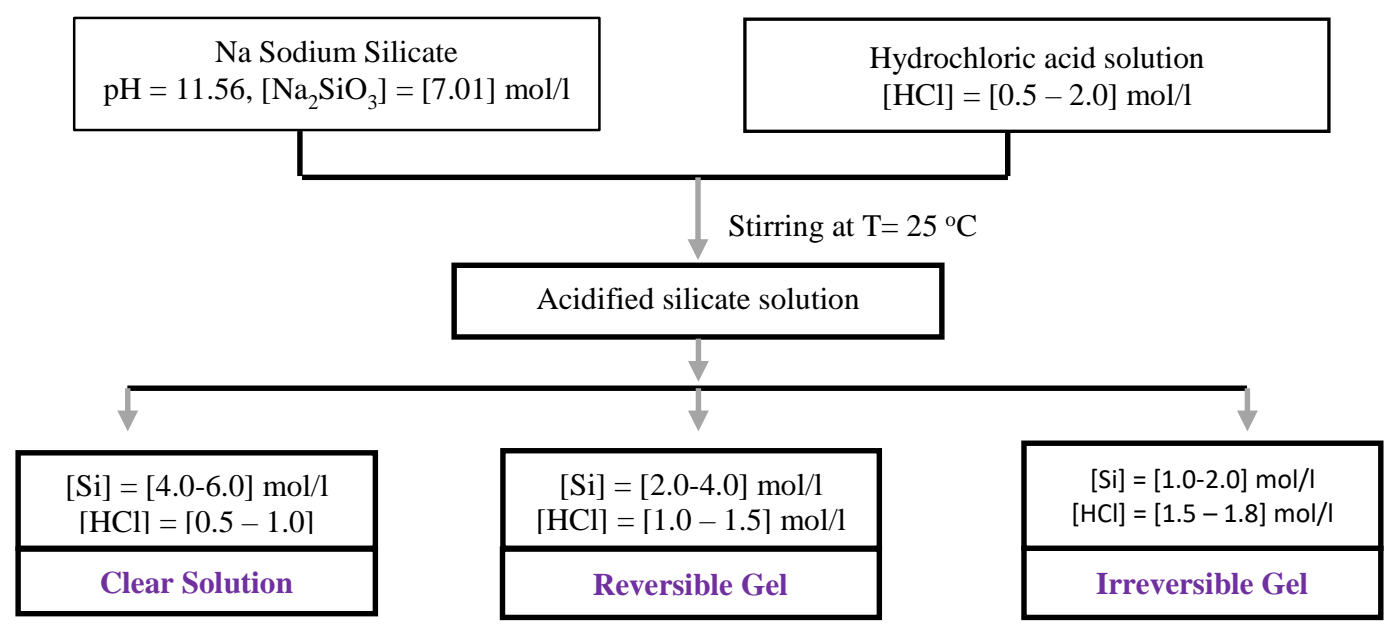

Fig. 1. Experimental process of products formation

\subsubsection{The maturation of products}

Depending on the concentration of hydrochloric acid and the concentration of sodium silicate, the maturation of the solutions can give three different products, in fact:

- "a" For a sodium silicate concentration between 4.0-6.0 mol/L and a hydrochloric acid concentration between $0.5-1.0 \mathrm{~mol} / \mathrm{L}$, a transparent and stable solution over time is obtained with an $11.26<\mathrm{ph}<11.56$ (Figure 2-a).
- "b" For a sodium silicate concentration between 2.0-4.0 $\mathrm{mol} / \mathrm{L}$ and a hydrochloric acid concentration between $1.0-1.5 \mathrm{~mol} / \mathrm{L}$ and $10.56<\mathrm{ph}<10.80$, we obtain a reversible gel, which gives, after maturation, two different phases (Figure 2-b).

- "c" For a concentration of sodium silicate between 1.0-2.0 $\mathrm{mol} / \mathrm{L}$ and a concentration of hydrochloric acid between 1.5-1.8 mol/l and $9.56<\mathrm{pH}<10.65$, an irreversible gel characterized by syneresis during maturation is obtained (Figure 2-c). 
The gelling time $(\mathrm{Tg})$ is the time elapsed between the preparation of the solution and the earliest moment at which the gel has come off the wall instead of flowing like a liquid when the beaker is inclined; this time can be determined ${ }^{7,8}$.
At the end of the repoussage, there is aphasic separation between the sediment and the supernatant for the reversible gel, and between the solid and the supernatant for the irreversible gel.

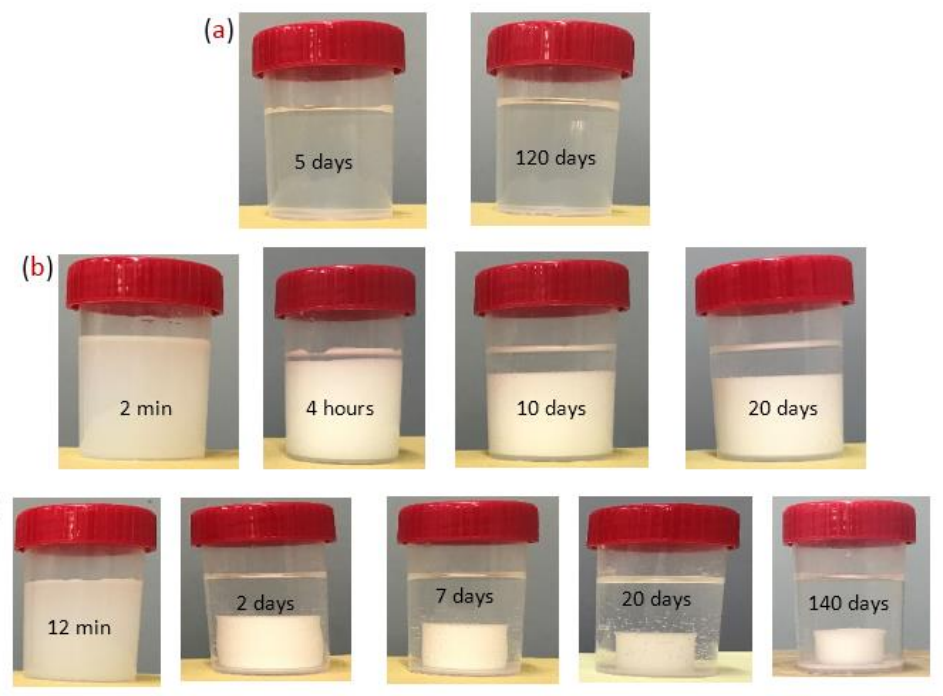

Fig. 2. Evolution of different solutions in maturation (a) Clear solution, (b) Reversible gel, (c) Irreversible gel

\subsection{Characterization techniques}

2.2.1. Scanning Electron Microscopy - Energy Dispersive (SEM-EDS) Spectroscopy

The morphology of the gel is observed using a Scanning Electron Microscope. The sample to be analyzed is taken employing a glass pipette and deposited in the hollow of a gold-plated copper grid provided with a hole in which the hydrated sample forms a thin layer suitable for rapid freezing and the formation of vitreous ice. The frozen sample is then transported to a microscope-type Gatan-type cold room where it is first fractured (cryofracture) and then heated to -155 to $-95^{\circ} \mathrm{C}$ to sublimate the surface ice. After this sublimation step, the sample is cooled in $5 \mathrm{~min}$ at $-150^{\circ} \mathrm{C}$. After metallization with gold for $40 \mathrm{~s}$, it is introduced on the cryogenic plate in the scanning electron microscope. The instrument is equipped with an energy dispersive spectrometer (EDS) system, for the analysis of the X-rays emitted by the sample to determine the elemental composition for elemental identification during SEM observations.

\subsubsection{Infrared absorption spectroscopy}

The structural analysis of the gel is obtained by using Infrared absorption spectroscopy. In the case of use in transmission mode, pellets are produced by uniaxial pressing at 6 bar from a mixture containing a mass of 1 to $4 \mathrm{mg}$ of the product previously parboiled at $110^{\circ} \mathrm{C}$ and mixed with $100 \mathrm{mg}$ of $\mathrm{KBr}$ dehydrated.

The acquisitions are made between 400 and $4000 \mathrm{~cm}^{-1}$, the number of scans is 20 and the resolution of $4 \mathrm{~cm}^{-1}$. OMNIC software (Nicolet instrument) is used for data acquisition and processing.

\subsubsection{X-ray Diffraction}

Powder X-ray diffraction patterns (XRD) are obtained using a Siemens 500 Kristalloflex X-ray Diffractometer (XRD) apparatus. Working with $\mathrm{CuK} \alpha$ radiation $(\lambda=1.5418 \AA), 40 \mathrm{kV}$ and a current of $30 \mathrm{~mA}$ were used. The samples, in the form of powdery powders, are deposited on the rotating sample holder to have the most planar surface possible. The exposure time for each sample is 20 minutes, and the measured angular range is from 10 to $90^{\circ}$.

\subsection{Computational methodology section}

The quantum methods that we have chosen in this study is density functional theory (DFT) ${ }^{23}$ combined to the exchange-correlation functional (B3LYP) ${ }^{24}$ with the basis $6-31 \mathrm{G}(\mathrm{d})$ level ${ }^{24}$. This is performed by the software materials such as Gaussian 09 program ${ }^{23}$ for the quantum calculation and Gauss View 5.0.8 ${ }^{25}$ for the structure visualizing. The optimization structure is confirmed by the following terms in the output file are signaled: Max Force (yes), RMS Force (yes), Max Displacement (yes), and RMS Displacement (yes). Global and local reactivity indices have been predicted. Finally, the water solvent is treated by using a relatively simple self-consistent reaction field (SCRF) based on the polarizable continuum model (PCM) of Tomasi group ${ }^{26}$.

The global electrophilicity, $\omega$, is given by the following expression, $\omega=\left(\mu^{2} / 2 \eta\right)^{27}$, in terms of the chemical potential, $\mu$, and the chemical hardness, $\eta$. Both quantities may be approached in terms of the one-electron energies of the frontier molecular orbitals HOMO and LUMO, $\varepsilon_{\mathrm{H}}$ and $\varepsilon_{\mathrm{L}}$, as $\mu \approx\left(\varepsilon_{\mathrm{H}}+\varepsilon_{\mathrm{L}}\right) / 2$ and $\eta=\left(\varepsilon_{\mathrm{L}}-\varepsilon_{\mathrm{H}}\right)$, respectively. The 
empirical (relative) global nucleophilicity $N$, based on the HOMO energies obtained within the Kohn-Sham scheme ${ }^{27}$, is defined as $N=\varepsilon_{\text {HOMO(Nucleophile) - }}$ $\varepsilon_{\text {номо }}$ (TCE) ${ }^{27}$, where tetracyanoethylene (TCE) is the reference because it presents the lowest HOMO energy in a large series of molecules already investigated in the context of polar organic reactions. The local electrophilicity, $\omega_{(\mathrm{k})}$, and the local nucleophilicity, $\boldsymbol{N}_{(\mathrm{k})}$, are evaluated by the Parr functions $\left(P_{k}^{+}, P_{k}^{-}\right)$according to the following formulas: $\omega_{(\mathrm{k})}=\omega . P_{k}^{+}$and $N_{(k)}=N . P_{k}^{-}{ }^{28}$. The electrophilic, $P_{k}^{+}$, and nucleophilic $P_{k}^{-}$, Parr functions, are obtained through the analysis of the Mulliken ASD of the radical anion and the radical cation by single-point energy calculations over the optimized neutral geometries using the unrestricted UB3LYP formalism for radical species.

\section{Results and discussion}

\subsection{Qualitative description of products}

\subsubsection{Clear and transparent solution}

Figure $2 \mathrm{a}$ shows that the solution obtained is homogeneous and formed of a single transparent, nongelling phase which is stable over time. This can only be explained by the fact that the concentration of $\mathrm{HCl}$ added $(0.5-1.0 \mathrm{~mol} / \mathrm{L})$ is low, whereas the concentration of sodium silicate is rather high (4.0-6.0 $\mathrm{mol} / \mathrm{L})$ and $11.26<\mathrm{ph}<11.56$. Therefore, the added $\mathrm{HCl}$ solution is not sufficient enough to ensure the hydrolysis of the hydroxyl groups of the sodium silicate solution.

\subsubsection{Reversible gel}

The product illustrated in Figure $2 b$ is obtained by the addition of hydrochloric acid solution (1.0-1.5 mol/L) to another alkaline solution of sodium silicate with a molar concentration ranging from $(2.0-4.0 \mathrm{~mol} / \mathrm{L})$ the $\mathrm{pH}$ of the solution measured is between $10.56<\mathrm{ph}<10.80$. The beginning of gelation is observed after a period of 10 to 60 seconds, characterized by a change in viscosity and color of the solution, which becomes more and whiter. From Figure 2-b shows that there is a significant contraction with a separation between the supernatant and the solid considered as sediment. This separation phenomenon begins after one hour and can go up to a maximum of 20 days. This is explained by the fact that the concentration of $\mathrm{HCl}$ favors a medium that is favorable to the formation of the gel. However, the gel obtained is reversible.

\subsubsection{Irreversible gel}

The third product (Figure 2c) is obtained by acidification of a sodium silicate solution $(1.0-2.0 \mathrm{~mol} / \mathrm{L})$ with $9.56<\mathrm{pH}<10.65$. Unlike the reversible gel, the contraction of this gel is delayed ( 2 days after the start of gelation) it can be noticed that the gel obtained is irreversible and is characterized by syneresis as a separation between the liquid phase and the solid gel. The consolidated product is not destroyed by mechanical agitation; temperature rise or water dilution ${ }^{14}$.

\subsection{Product characterizations \\ 3.2.1. Reversible Gel}

Maturation of the reversible gels results in the slow formation of a white solid with progressive anisotropic shrinkage and a supernatant liquid obtained $20 \mathrm{~min}$ after gelation. The resulting solid is characterized by scanning electron microscopy, X-Ray Diffraction and FTIR spectroscopy.

\subsubsection{Scanning Electron Microscopy - Energy Dispersive (SEM-EDS) Spectroscopy}

The scanning electron microscope has been used at a working acceleration voltage of between 1 and $6 \mathrm{kV}$, under conditions that achieve magnifications of 200,000 for secondary electron images. The result obtained (Figure 3) shows that the gel is formed by dense clusters with a homogeneous surface.
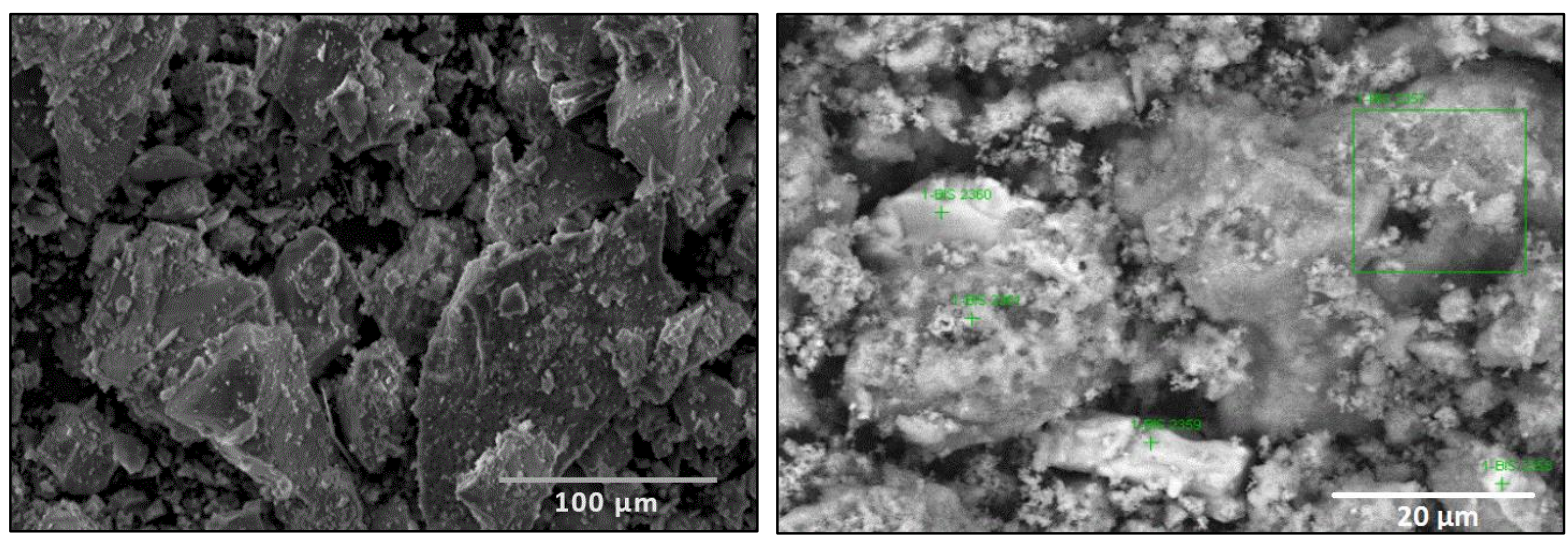

Fig. 3. Scanning Electronic Microscopy of reversible gel 
The EDS analysis results presented in Figure 4 gives the elemental composition of the solid. These results clearly illustrate the presence of silicon and oxygen, with a low percentage by weight of chlorine and sodium, and a trace of carbon.

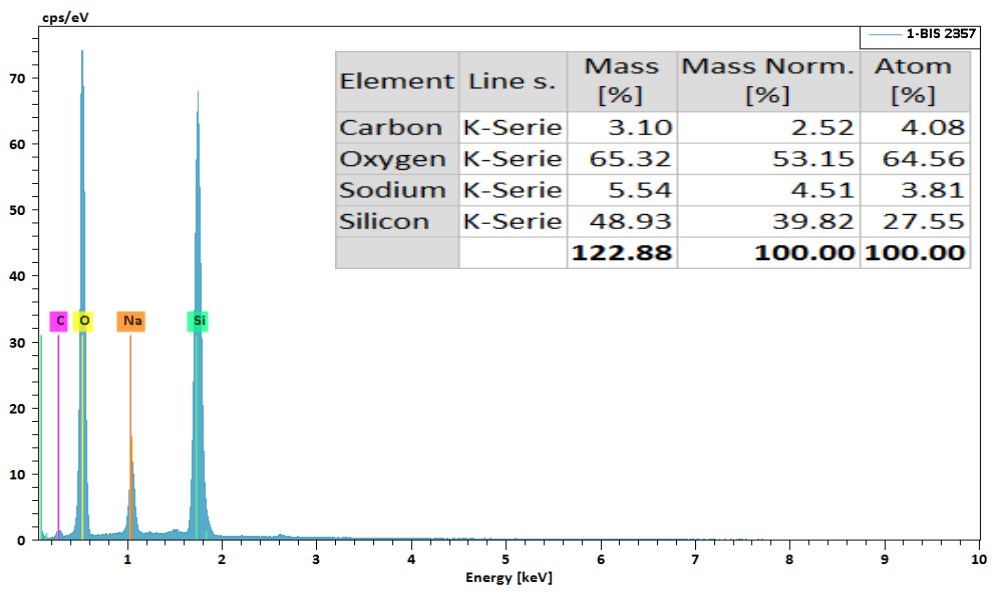

Fig. 4. EDS Chemical analysis of reversible gel

As can be seen from the analysis table (Figure 4), the solid formed is characterized by high contents of silicon (36.96 to $39.82 \mathrm{w} . \%)$ And oxygen (53, 15 to 57.00 w.\%). These data confirm the results of previous analyzes XRD IFTR. From these analyses it can conclude that the solid formed is rich in silicon and oxygen, responsible of the formation of $\mathrm{SiO}_{2}{ }^{8}$.

\subsubsection{Infrared absorption spectroscopy}

Analysis by infrared absorption spectroscopy (Figure 5) showed the existence of several bands, notably the bands relating to the bending of the water molecules $\left(\delta \mathrm{H}_{2} \mathrm{O}\right)$ in 1640 and $3436 \mathrm{~cm}^{-1}$, two significant peaks at 771 and $1033 \mathrm{~cm}^{-1}$ belong to the asymmetric stretching of the $\mathrm{Si}-\mathrm{O}-\mathrm{Si}$ bond, as well as the Si-O-Na band in $943 \mathrm{~cm}^{-1}$. The last peak at $787 \mathrm{~cm}^{-1}$ belongs to the vibration of $\mathrm{Si}-\mathrm{O}-\left(\mathrm{Na}^{+}\right)^{8,12}$.

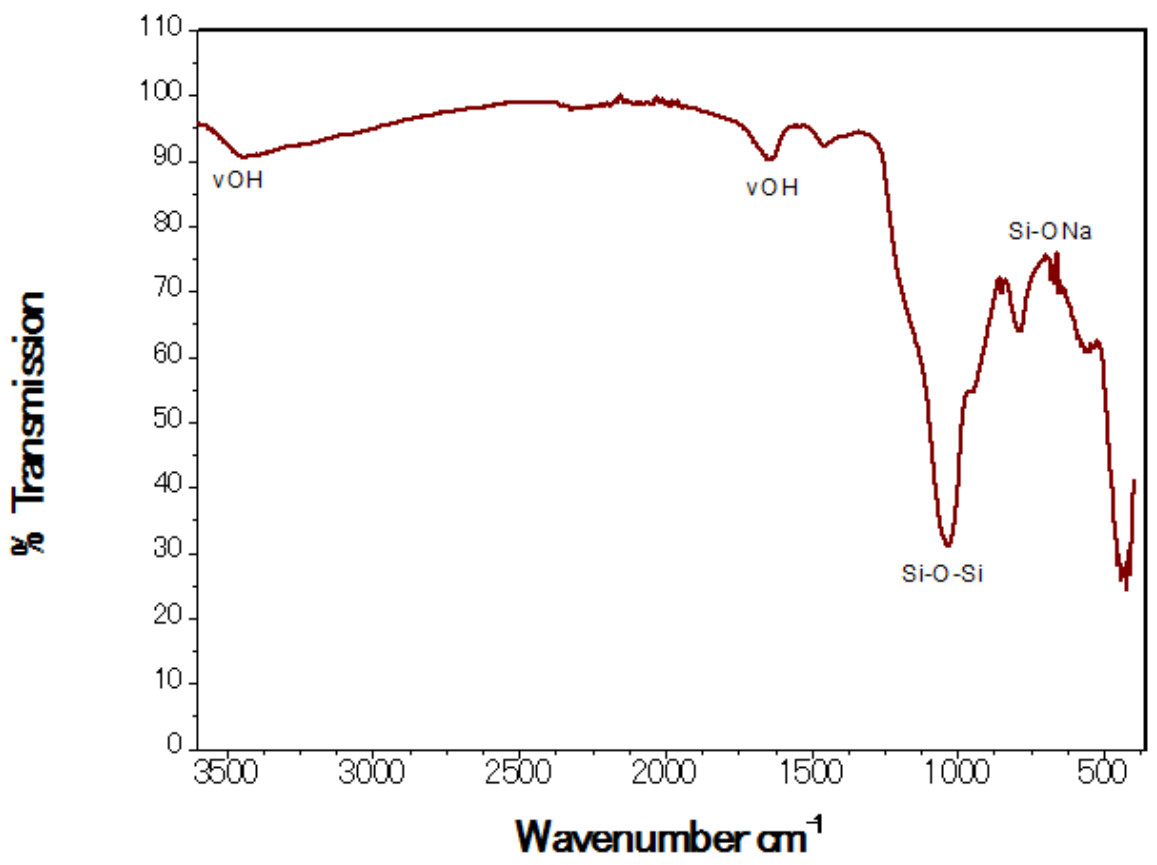

Fig. 5. Infrared Absorption Spectrum of the Reversible Gel

\subsubsection{Irreversible Gel}

After complete gelation, the appearance of syneresis is observed (Figure 3-c). This phenomenon is characterized by a total discharge of the liquid contained in the gelled phase. The gel obtained is irreversible. The dilution of the gel in water with vigorous stirring or its drying in an oven heated to a temperature of $70^{\circ} \mathrm{C}$ for 24 hours does not influence it is the appearance ${ }^{10}$.

\subsubsection{X-ray Diffraction}

The X-ray diffraction patterns are obtained using a diffractometer dedicated to the characterization of polycrystalline plane samples. The structural analysis of the irreversible gel is performed for a solid obtained 
after 4 months of aging, and after drying at room temperature for 48 hours.

The structural analysis of the irreversible gel obtained (Figure 6) shows that the gel is composed of two phases: An amorphous phase characteristic of the irreversible gel and a well-crystallized phase

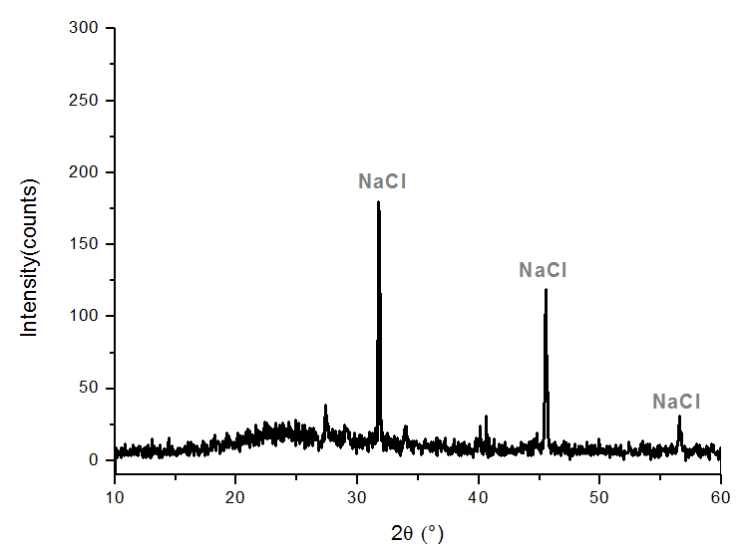

Fig. 6. Diffractogram of the X-rays of the solid (irreversible gel)

\subsubsection{Scanning Electron Microscopy - Energy Dispersive (SEM-EDS) Spectroscopy}

The microstructure of an irreversible gel obtained shows that the microstructural character of irreversible gels during maturation is quite similar to that of reversible gels (Figure 8).

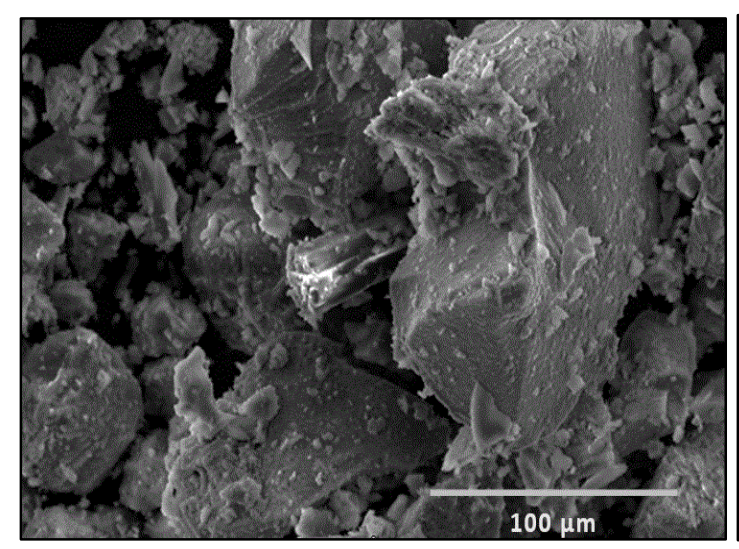

characteristic of $\mathrm{NaCl}$. The appearance of the crystalline peaks of $\mathrm{NaCl}$ is explained by the fact that the solid does not undergo a wash after the formation of the solid. Noting well that after washing and drying the product, the crystalline peaks of $\mathrm{NaCl}$ are disappeared from the spectrum (Figure 7) ${ }^{62}$.

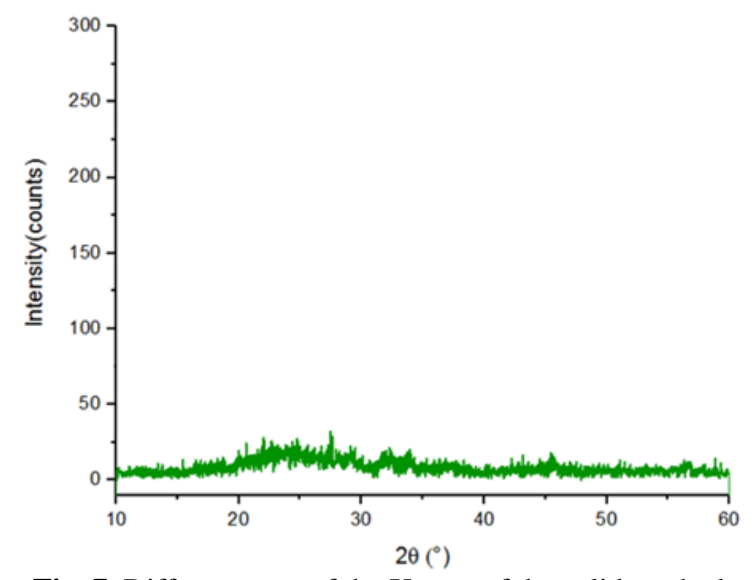

Fig. 7. Diffractogram of the X-rays of the solid washed and dried (irreversible gel)

Apart from the $\mathrm{NaCl}$ fragments which occupy the surface of the solid analyzed, it can be seen that the solid reflects a delicate appearance, because even its resistance to dilution by water or temperature, its mechanical behavior remains low. This is expressed by its amorphous nature. Also, the solid is characterized by a homogeneous surface without the appearance of pores ${ }^{12}$.

Fig. 8. Scanning electron microscopy of the irreversible gel

Figure 9 shows the presence of silicon, oxygen, sodium, chlorine and traces of carbon from the gelation reaction of alkaline sodium silicate. As can be seen from the EDS analysis, the solids are characterized by high contents of silicon (from 39.67 to $61.65 \mathrm{wt} . \%$ ) And oxygen (8.45 to $41.66 \mathrm{wt} . \%$ ). The comparison of these results with the reversible gel analysis shows that the high rate of silicon and oxygen is responsible for the strong consolidation of the irreversible solid characterized by high $\mathrm{SiO}_{2}$ content ${ }^{8}$.

We also note that the EDS analysis shows a low percentage of sodium and chloride $(<21.02 \mathrm{wt} . \%$ and wt. $\%<12.75$ respectively). 


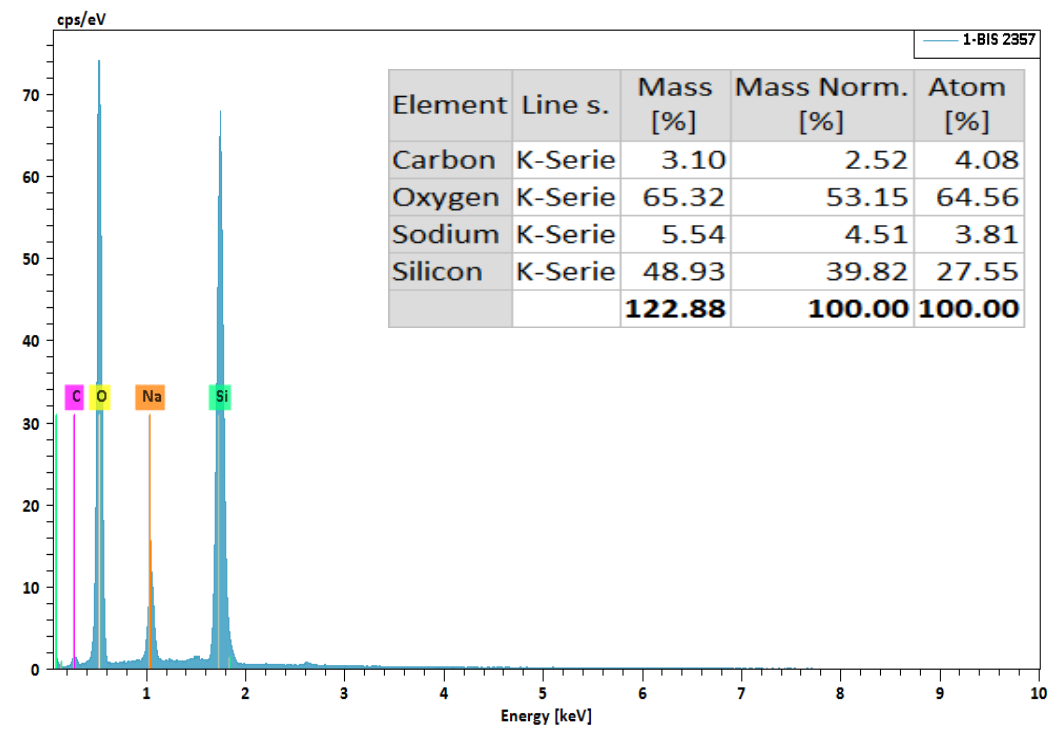

Fig. 9. EDS Chemical analysis of irreversible gel

\subsubsection{Infrared spectroscopy}

To confirm the representative chemical bonds of the irreversible gel, the FTIR spectrum of the solid analyzed is recorded (Figure 10). The bands shown in the IR spectra correspond to the $\mathrm{OH}$ vibration band of water $3422 \mathrm{~cm}^{-1}$, bending of water molecules $\left(\delta \mathrm{H}_{2} \mathrm{O}\right)$ $\left(1640 \mathrm{~cm}^{-1}\right)$, a significant peaks appearing at $1033 \mathrm{~cm}^{-}$ ${ }^{1}$ was covered by the asymmetric stretching of the $\mathrm{Si}$ $\mathrm{O}-\mathrm{Si}$ bond (vas $\mathrm{Si}-\mathrm{O}-\mathrm{Si}$ ), and $552 \mathrm{~cm}^{-1}$ is attributed to the flexural vibration mode of $\mathrm{O}-\mathrm{Si}-\mathrm{O}$. The appearance of a small peak near to $950 \mathrm{~cm}^{-1}$ belongs to the bending vibration of $\mathrm{Si}-\mathrm{OH}$ while $787 \mathrm{~cm}^{-1}$ was caused by the vibration of $\mathrm{Si}-\mathrm{O}-\left(\mathrm{Na}^{+}\right)^{12}$.

Moreover, the Si-OH and SI-O-Si bands characterizing the irreversible gel have a large amplitude relative to the reversible gel spectrum. This is expressed by the high cohesion of the irreversible gel characterized by strong bonds of $\mathrm{Si}-\mathrm{O}-\mathrm{Si}$, responsible for the final formation of the consolidated material ${ }^{8}$.

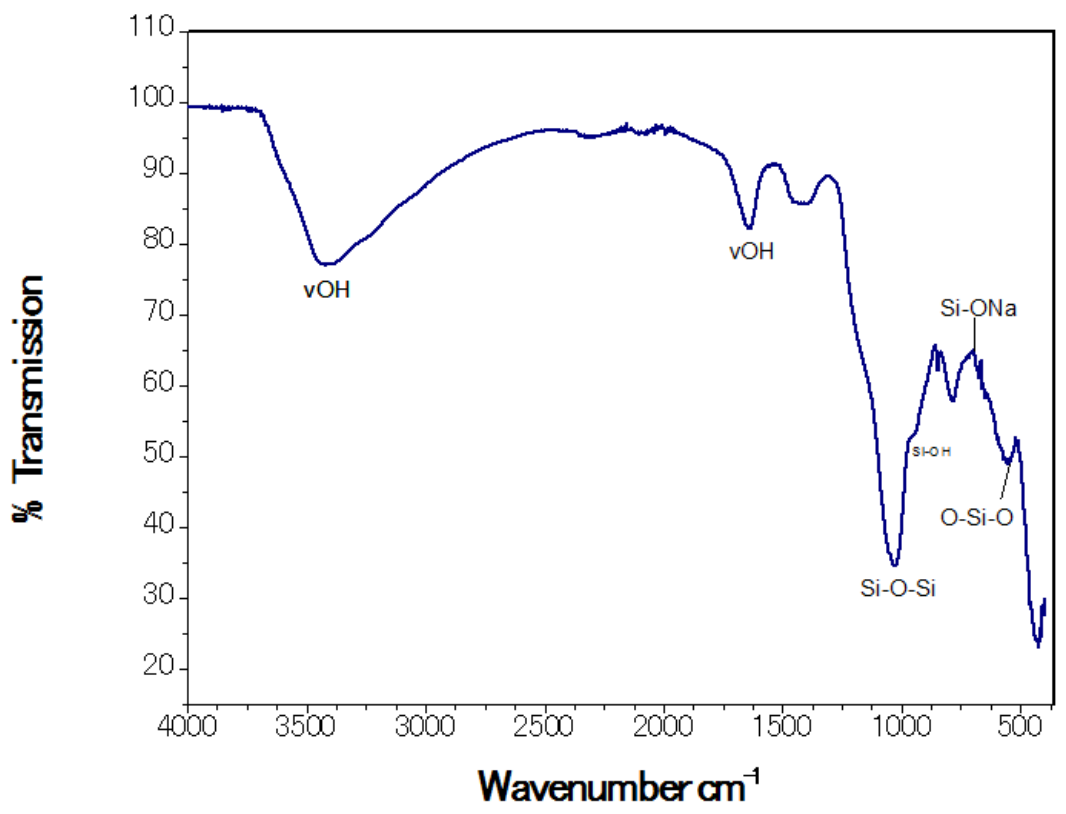

Fig. 10. Infrared absorption spectrum of irreversible gel

\subsection{Computational study}

\subsubsection{Optimized geometry of reagents}

Reagents optimization is required to start this study. The numbering of the atoms for both reagents is illustrated in Figure 11. Some bond angles and binding lengths of those reagents are listed in Table 1.

Through optimized geometry of sodium silicate (Figure 11), it can be noticed that the two hydroxyl groups $(-\mathrm{OH})$ bonded to silica atoms $(\mathrm{Si}(7)$ and $\mathrm{Si}(9)$ 
) have a cis form, while those linked to silica atoms ( $\mathrm{Si}(6)$ and $\mathrm{Si}(8))$ have a trans form. On the other hand, the binding lengths $(\mathrm{Si}-\mathrm{O})$ and the binding angles (Si-O-Si) do not have the same values (Table 1). This result could be explained by the fact that the atoms of sodium silicate are arranged differently from each other in space. This calculation information has not been demonstrated by previous studies ${ }^{29,30}$.

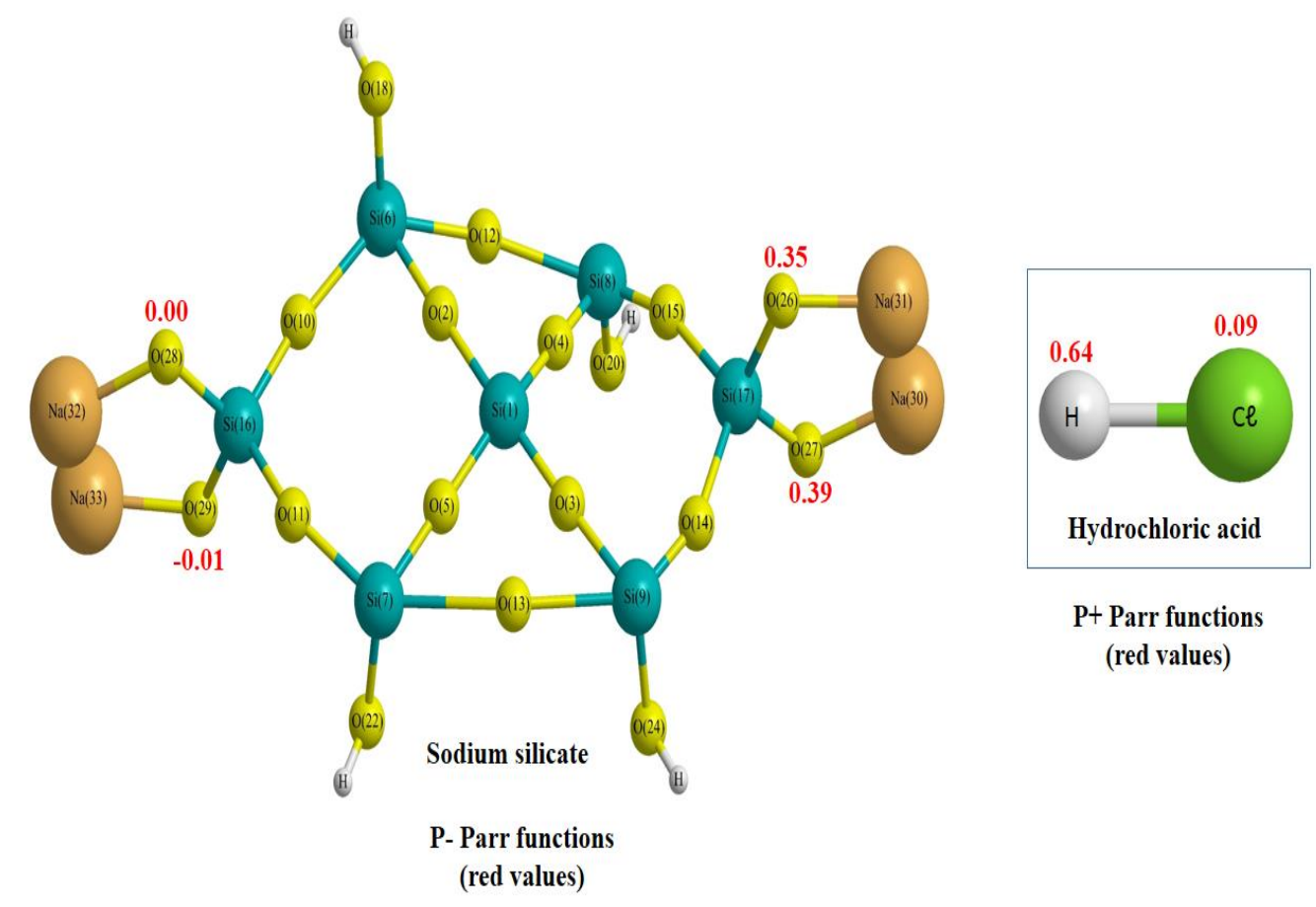

Fig.11. Optimized geometry of reagents, electrophilic P+ Parr function of hydrochloric acid and nucleophilic P- Parr function of sodium silicate

Table 1. Binding lengths (in angstrom) and bond angles of sodium silicate in water as solvent Sodium silicate.

\begin{tabular}{|c|c|c|c|}
\hline Binding lengths & Binding value & Bond angles & *Angle value \\
\hline $\mathrm{Si}_{1}-\mathrm{O}_{2}$ & 1.979 & $\mathrm{Si}_{9} \mathrm{O}_{13} \mathrm{Si}_{7}$ & 121.676 \\
\hline $\mathrm{Si}_{1}-\mathrm{O}_{3}$ & 2.044 & $\mathrm{Si}_{6} \mathrm{O}_{12} \mathrm{Si}_{8}$ & 121.392 \\
\hline $\mathrm{Si}_{1}-\mathrm{O}_{4}$ & 1.965 & $\mathrm{Si}_{8} \mathrm{O}_{4} \mathrm{Si}_{1}$ & 87.396 \\
\hline $\mathrm{Si}_{1}-\mathrm{O}_{5}$ & 1.969 & $\mathrm{Si}_{6} \mathrm{O}_{2} \mathrm{Si}_{1}$ & 127.617 \\
\hline $\mathrm{O}_{27}-\mathrm{Na} 30$ & 11.142 & $\mathrm{Si}_{7} \mathrm{O}_{5} \mathrm{Si}_{1}$ & 130.975 \\
\hline $\mathrm{O}_{26}-\mathrm{Na} 31$ & 12.355 & $\mathrm{Si}_{9} \mathrm{O}_{3} \mathrm{Si}_{1}$ & 106.213 \\
\hline $\mathrm{O}_{28}-\mathrm{Na} 32$ & 12.296 & $\mathrm{O}_{4} \mathrm{Si}_{1} \mathrm{O}_{2}$ & 97.921 \\
\hline $\mathrm{O}_{29}-\mathrm{Na}_{33}$ & 11.132 & $\mathrm{O}_{3} \mathrm{Si}_{1} \mathrm{O}_{5}$ & 99.473 \\
\hline $\mathbf{S i}_{16}-\mathrm{O}_{28}$ & 1.830 & $\mathrm{O}_{3} \mathrm{Si}_{1} \mathrm{O}_{4}$ & 80.147 \\
\hline $\mathrm{Si}_{16}-\mathrm{O}_{29}$ & 1.830 & $\mathrm{O}_{5} \mathrm{Si}_{1} \mathrm{O}_{2}$ & 82.456 \\
\hline $\mathrm{Si}_{17}-\mathrm{O}_{26}$ & 1.550 & $\mathrm{O}_{14} \mathrm{Si}_{17} \mathrm{O}_{15}$ & 129.244 \\
\hline $\mathbf{S i}_{17}-\mathbf{O}_{27}$ & 1.600 & $\mathrm{O}_{11} \mathrm{Si}_{16} \mathrm{O}_{10}$ & 124.580 \\
\hline $\mathrm{Si}_{6}-\mathrm{O}_{2}$ & 1.771 & $\mathrm{O}_{3} \mathrm{Si}_{9} \mathrm{O}_{14}$ & 82.905 \\
\hline $\mathrm{Si}_{4}-\mathrm{O}_{8}$ & 2.120 & $\mathrm{O}_{4} \mathrm{Si}_{8} \mathrm{O}_{15}$ & 84.603 \\
\hline $\mathrm{Si}_{9}-\mathrm{O}_{3}$ & 2.101 & $\mathrm{O}_{2} \mathrm{Si}_{6} \mathrm{O}_{10}$ & 121.676 \\
\hline $\mathrm{Si}_{7}-\mathrm{O}_{5}$ & 1.603 & $\mathrm{O}_{5} \mathrm{Si}_{7} \mathrm{O}_{11}$ & 121.392 \\
\hline $\mathrm{Si}_{6}-\mathrm{O}_{12}$ & 1.930 & $\mathrm{O}_{27} \mathrm{Si}_{17} \mathrm{O}_{26}$ & 127.116 \\
\hline $\mathrm{Si}_{8}-\mathrm{O}_{12}$ & 1.891 & $\mathrm{O}_{29} \mathrm{Si}_{16} \mathrm{O}_{28}$ & 127.257 \\
\hline $\mathrm{Si}_{7}-\mathrm{O}_{13}$ & 2.567 & $\mathrm{Na}_{30} \mathrm{O}_{27} \mathrm{Si}_{17}$ & 142.914 \\
\hline $\mathrm{Si}_{9}-\mathrm{O}_{13}$ & 1.984 & $\mathrm{Na}_{31} \mathrm{O}_{26} \mathrm{Si}_{17}$ & 141.371 \\
\hline $\mathrm{Si}_{7}-\mathrm{O}_{22}$ & 1.830 & $\mathrm{Na}_{33} \mathrm{O}_{29} \mathrm{Si}_{16}$ & 122.952 \\
\hline $\mathrm{Si}_{9}-\mathrm{O}_{24}$ & 1.730 & $\mathrm{Na}_{32} \mathrm{O}_{28} \mathrm{Si}_{16}$ & 121.897 \\
\hline $\mathrm{Si}_{8}-\mathrm{O}_{20}$ & 1.520 & & \\
\hline $\mathrm{Si}_{6}-\mathrm{O}_{18}$ & 1.470 & & \\
\hline
\end{tabular}

*Angle values are given by degree unit 


\subsubsection{Analysis of the CDFT reactivity descriptors at the ground state of reagents}

In this part, we will display the reactivity of reagents between sodium silicate and hydrochloric acid within the conceptual DFT (CDFT), for which the global reactivity indexes defined via the CDFT. They are potent tools to clarify the reactivity in this reaction. Table 2 regrouped the global DFT reactivity indices, namely electronic chemical potential, $\mu$, chemical hardness, $\eta$, electrophilicity, $\omega$, and nucleophilicity, $N$, for two reagents.

Table 2. B3LYP/6-31G (d) electronic chemical potential, $\mu$, chemical hardness, $\eta$, global electrophilicity, $\omega$, and global nucleophilicity, $\mathrm{N}$, indices, in $\mathrm{eV}$, for sodium silicate and hydrochloric acid.

\begin{tabular}{|l|c|c|c|c|c|c|}
\hline & $\boldsymbol{\varepsilon}_{\mathbf{H}}$ & $\boldsymbol{\varepsilon}_{\mathbf{L}}$ & $\boldsymbol{\mu}$ & $\boldsymbol{\eta}$ & $\boldsymbol{\omega}$ & $\boldsymbol{N}$ \\
\hline Sodium silicate & -6.54 & -0.75 & -3.65 & 5.79 & 1.15 & 2.20 \\
\hline Hydrochloric acid & -9.07 & 0.60 & -4.84 & 8.46 & 1.38 & null \\
\hline
\end{tabular}

Regarding the results depicted in Table 2, sodium silicate presents a considerable electronic chemical potential $(-3.65 \mathrm{eV})$ than that hydrochloric acid $(-4.84$ $\mathrm{eV}$ ), suggesting that along this reaction the global electronic density transfer (GEDT) will take place from the first toward the latter. The nucleophilicity value gives a height nucleophilicity of the sodium silicate moiety to be $2.20 \mathrm{eV}$ to compare with that of hydrochloric acid, null nucleophilicity. Therefore, the electrophilicity index of this latter reagent is mostly higher, $1.38 \mathrm{eV}$, compared with that of the sodium silicate, which has $1.15 \mathrm{eV}$. This result indicates that the hydrochloric acid acts as an electrophile, whereas the sodium silicate performs as a nucleophile in this 32CA reaction.

A tiny attention is funded to the regio-chemistry. At this stage, while an electrophile and electrophile approach to each other, a very valuable electronic effect are afraid. The nucleophilic $\mathrm{P}-$ and electrophilic P+ Parr functions are mostly considered as a dominant outfit to examining local regioselectivity in polar processes, though such functions are commonly derived from the excess of spin electron density reached via the GEDT process from the nucleophile to the electrophile. They state that the most favorable reactive channel is determined by the initial two-center interaction between the most electrophilic center of the electrophile and the most nucleophilic center of the nucleophile. Figure 10 shows the principally appreciable interactions between the most power electrophilic and nucleophilic sites. Indeed, the calculated nucleophilic Firstly, $\mathrm{P}-$ Parr function at $\mathrm{O}(26)$ and $\mathrm{O}(27)$ oxygen atoms of sodium silicate, 0.35 and 0.39 , respectively, are significantly larger than that of others oxygen atoms $\mathrm{O}(28)$ and $\mathrm{O}(29)$ indicating strongly $\mathrm{O}(26)$ and $\mathrm{O}(27)$ atoms are the most nucleophilic sites at sodium silicate moiety for which will be much more activated than $\mathrm{O}(28)$ and $\mathrm{O}(29)$ towards an electrophilic attack. Secondly, electrophilic P+ Parr function at the reactive sites of hydrochloric acid indicates that the hydrogen atom, with a value equal to 0.64 , is the most electrophilic site to compare with that of the chlorine atom which has a $\mathrm{P}+$ value of 0.09 .

Consequently, affording to the analysis of the Parr functions, the mainly appreciated interactions in this reaction will take place between the most nucleophilic sites at the sodium silicate, $\mathrm{O}(26)$ and $\mathrm{O}(27)$, and the most electrophilic site at the hydrochloric acid, the hydrogen atom. In good agreement with the regioselectivity experimentally observed ${ }^{18}$. These computational results have not been shown by previous studies ${ }^{29,30}$.

\subsubsection{Infrared Spectroscopy obtained by Computational DFT}

The infrared spectrum obtained by the CDFT method (Figure 12), shows the existence of several peaks confirming the formation of a silicate product. Initially, two vibrations of the $\mathrm{OH}$ group $(\mathrm{vOH})$ water are observed at 3055 and $3422 \mathrm{~cm}^{-1}$. Two significant peaks appeared in the bands 1045 and $715 \mathrm{~cm}^{-1}$, these bands are responsible for the asymmetrical stretching of the Si-O-Si. It is noted at the end the existence of a small peak near to $950 \mathrm{~cm}^{-1}$ belonged to the vibration of $\mathrm{Si}-\mathrm{O}-\left(\mathrm{Na}^{+}\right)$. Finally, a band near to $550 \mathrm{~cm}^{-1}$ belonged to the bending of O-Si-O. These theoretical analysis results reflect a high similarity with previous experimental analysis (Figure 5 and Figure 10) ${ }^{12,27 .}$ 


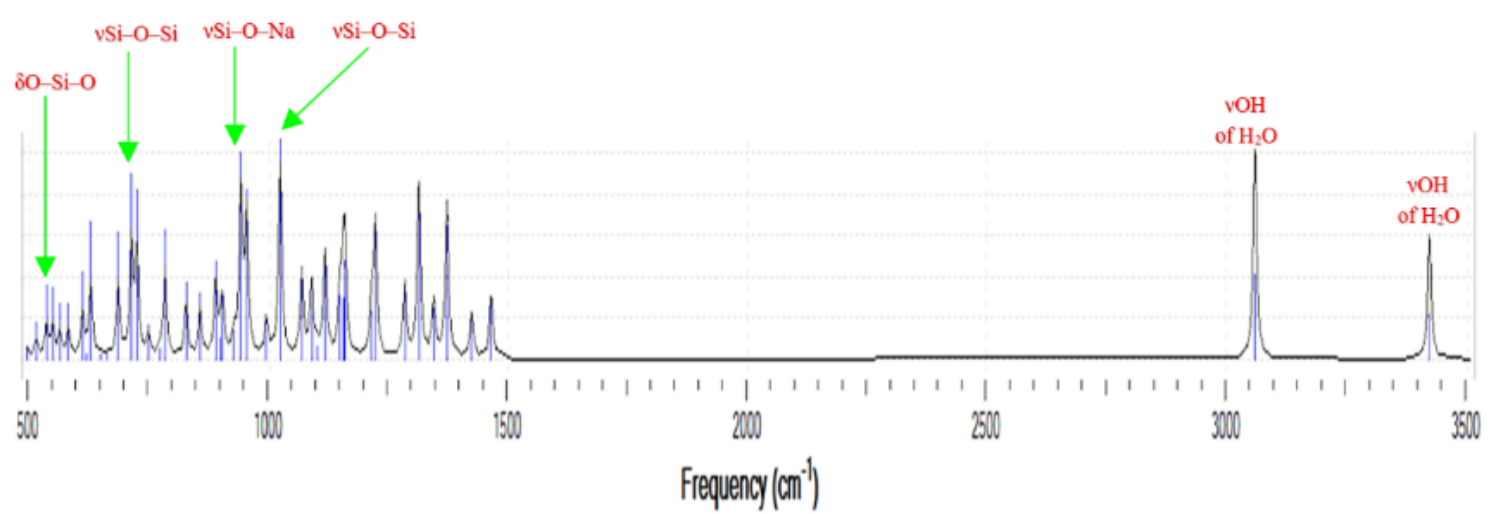

Fig. 12. Theoretical IR spectrum obtained by CDFT

\section{Conclusion}

The acidification of sodium silicate gives three types of products, namely the clear solution, the reversible and irreversible gel. In order to understand the nature and the compositions of the gels, the study of these products imposed a tracking of their behavior as well as their characterization by physicochemical methods. The microstructural analyzes of the two gels revealed that these obtained solids are almost similar whereas the structural and elementary analyzes show that the silica content in the irreversible gel is higher than the silica content in the reversible gel.

The optimization by DFT of the reaction between hydrochloric acid and sodium silicate indicated that hydrochloric acid is an electron acceptor and that sodium silicate is an electron donor, which is a right consistency with the experimental result. Therefore, the most nucleophilic centers of the sodium silicate are the oxygen atoms $\left(\mathrm{O}_{(26)}\right.$ and $\left.\mathrm{O}_{(27)}\right)$ and the most electrophilic center of the hydrochloric acid is the hydrogen atom. However, we have noticed that the oxygen atoms $\left(\mathrm{O}_{(28)}\right.$ and $\left.\mathrm{O}_{(29)}\right)$ of sodium silicate are reactive with hydrochloric acid.

\section{References}

1- J. Davidovits, L. Huaman, R. Davidovits, Ancient geopolymer in the South-American monument. SEM and petrographic evidence, Journal of Materials Letters, 2019, 35, 120-124.

2- Z. Yunsheng, S. Wei, L. Zonglin, Composition design and microstructural characterization of calcined kaolin-based geopolymer cement. Journal of Applied Clay Science, 2010, 47, 271-275.

3- A. Autef, E. Prud'homme, E. Joussein, G. Gasgnier, S. Pronier, S. Rossignol, Evidence of a gel in geopolymer compounds from pure metakaolin. Journal of Sol-Gel Science and Technology, 2013, 67, 543-544.

4- A.S. De Vargas, D.C.C. Dal Molin, A.C.F. Vilela, F.J. Da Silva, B. Pavao, H. Veit, The effects of $\mathrm{Na}_{2} \mathrm{O} / \mathrm{SiO}_{2}$ molar ratio, curing temperature and age on compressive strength, morphology and microstructure of alkali- activated fly ash-based geopolymers. J. Cem. Concr. Compos., 2011, 33(6), 653-660.

5- A.S. De Vargas, D.C.C. Dal Molin, A.C.F. Vilela, F.J. Da Silva, B. Pavao, H. Veit, The effects of $\mathrm{Na}_{2} \mathrm{O} / \mathrm{SiO}_{2}$ molar ratio, curing temperature and age on compressive strength, morphology and microstructure of alkaliactivated fly ash-based geopolymers, J. Cem. Concr. Compos., 2011, 33(6), 653-660.

6- X. Guo, H. Huisheng Shi, W.A. Dick, Compressive strength and microstructural characteristics of class C fly ash geopolymer, Journal of Cement \& Concrete Composites, 2010, 32, 142-147.

7- K. Komnitsas, D. Zaharaki, Geopolymerisation: a review and prospects for the minerals industry, $J$. Miner. Eng., 2007, 20(14), 1261-1277.

8- M.T. Tognonvi, S. Rossignol, J. Bonnet, Effect of alkali cation on irreversible gel formation in basic medium, Journal of Non-Crystalline Solids, 2011, 357, 43-49.

9- P.B. Sarawade, J.K. Kim, A. Hilonga, H.T. Kim, Production of low-density sodium silicate-based hydrophobic silica aerogel beads by a novel fast gelation process and ambient pressure drying process, Journal of Solid State Sciences, 2010, 12, 911-918.

10-M.T.Tognonvi, J. Soro, S. Rossignol, Physicalchemistry of silica/alkaline silicate interactions during consolidation. Part 1: Effect of cation size, Journal of Non-Crystalline Solids, 2012, 358, 81-87.

11- A.M. Ismail, A.A. Menazea, H.A. Kabary, A.E. El-Sherbiny, A. Samy, The influence of calcination temperature on structural and antimicrobial characteristics of Zinc Oxide nanoparticles synthesized by Sol-Gel method. Journal of Molecular Structure, 2019, 1196, 332-337.

12- M.T. Tognonvi, S. Rossignol, J. Bonnet, Physical-chemistry of sodium silicate gelation in an alkaline medium, J. Sol-Gel Sci Technol., 2011, 58, 625-635.

13-M.T. Tognonvi, A. Lecomte, S. Rossignol, J-P. Bonnet, Ripening of Na-silicate gels in basic 
media: Identification of involved chemical species, Journal of Non-Crystalline Solids, 2019 , 522, 1194821.

14-Y. Yu, M. Wang, D. Zhang, B. Wang, G. Sant, M. Bauchy, Stretched Exponential Relaxation of Glasses at Low Temperature, Journal Phys. Rev. Lett., 2015, 115, 165901.

15-S. Gutzov, N. Danchova, S. Karakashev, M. Khristov, J. Ivanova, J. Ulbikas, Preparation and thermal properties of chemically prepared nanoporous silica aerogels, J. Sol-Gel Sci. Technol., 2014, 70, 511-516.

16-M.T. Tognonvi, D. Massiot, A. Lecomte, S. Rossignol, J.P. Bonnet, Identification of solvated species present in concentrated and dilute sodium silicate solutions by combined $29 \mathrm{Si}$ NMR and SAXS studies, J.Colloid Interface Sci., 2010, 352, 309-315.

17-C.M. Sorensen, A. Chakrabarti, The sol to gel transition in irreversible particulate systems, Journal Soft Matter, 2011, 7, 2284-2296.

18-Y. Zhang, Y. Li, R. Chen, Y. Wang, J. Deng, X. X. Luo, Flotation Separation of Scheelite from Fluorite Using Sodium Polyacrylate as Inhibitor, J. Minerals, 2017, 7, 102.

19-P. Geerlings, F. De Proft, W. Langenaeker, Conceptual density functional theory, Chem. Rev., 2003, 103, 1793-1873.

20-L.R. Domingo, M. Rios-Gutierrez, P. Perez, Applications of the conceptual density functional theory indices to organic chemistry reactivity, Journal Molecules, 2016, 21, 748-751.

21-M.R. Sadat, S. Bringuier, K. Muralidharan, K. Runge, A. Asaduzzaman, L. Zhang, An atomistic characterization of the interplay between composition, structure and mechanical properties of amorphous geopolymer binders, J. Non-Cryst. Solids, 2016, 434, 53-61.

22-A. Bagheri, A. Nazari, J.G. Sanjayan, P. Rajeev, W. Duane, Fly ash-based boroaluminosilicate geopolymers: Experimental and molecular simulations, J. Ceram. Int., 2017, 43, 4119-4126.
23-K.V. Tian, M.Z. Mahmoud, P. Cozza, S. Licoccia, D. Fang, D. Di Tommaso, G.A. Chass, G. NevilleGreaves, Periodic vs. molecular cluster approaches to resolving glass structure and properties: Anorthite a case study, J. Non-Cryst. Solids, 2016, 451, 138-145.

24-M.J. Frisc, G.W. Trucks, G.B. Schlegel, et al., Gaussian 09, evision A.02, Gaussian Inc, Wallingford, 009.

25-R. Dennigton, T. Keith, J. Millam, Molecular Docking of Slective Binding Affinity of Sulfonamide Derivatives as Potential Antimalarial Agents Targeting the Glycolytic Enzymes: GAPDH, Aldolase and TPI, GaussView. Version 5. Semichem Inc. Shawnee Mission. KS, 2009.

26-J. Tomasi, M. Persico, Molecular Interactions in Solution: An Overview of Methods Based on Continuous Distributions of the Solvent, Chem. Rev., 1994, 94, 2027-2094.

27-L.R. Domingo, E. Chamorro, P. Pérez, Understanding the Reactivity of Captodative Ethylenes in Polar Cycloaddition Reactions. A Theoretical Study, J. Org. Chem., 2008, 73, 4615-4624.

28-L.R. Domingo, P. Pérez, J.A. Sáez, Understanding the local reactivity in polar organic reactions through electrophilic and nucleophilic Parr functions, RSC Adv., 2013, 3, 1486-1494.

29-S.S. Kouassi, M.T. Tognonvi, J. Soro, S. Rossignol, Consolidation mechanism of materials obtained from sodium silicate solution and silicabased aggregates, Journal of Non-Crystalline Solids, 2011, 357, 3013-3021.

30-S. Lucas, M.T. Tognonvi, J.L. Gelet, J. Soro, S. Rossignol, Interactions between silica sand and sodium silicate solution during the consolidation process, Journal of Non-Crystalline Solids, 2011, 357, 1310-1318. 